DOSSIÊ TEMÁTICO: Educação, currículo e juventudes: dilemas e desafios atuais

d. https://doi.org/10.22481/praxisedu.v16i42.7338

\title{
FORMAR PROFESSORES PARA A EDUCAÇÃO DE PESSOAS JOVENS E ADULTAS NA AMÉRICA LATINA: UM CAMPO EM DEFINIÇÃO
}

\author{
TRAINING TEACHERS FOR THE EDUCATION OF YOUNG AND ADULT PEOPLE IN \\ LATIN AMERICA: A FIELD IN DEFINITION \\ FORMAR PROFESORES PARA LA EDUCACIÓN DE JÓVENES Y ADULTOS EN \\ AMÉRICA LATINA: UN CAMPO EN DEFINICIÓN
}

\author{
Adenilson Souza Cunha Júnior \\ Universidade Estadual do Sudoeste da Bahia - Brasil
}

Lê̂ncio José Gomes Soares

Universidade Federal de Minas Gerais - Brasil

\begin{abstract}
Resumo: Objetivamos neste estudo apresentar através de uma análise panorâmica as principais tendências e tensões existentes no campo da formação de professores para a Educação de Pessoas Jovens e Adultas (EPJA) na América Latina. O reconhecimento da EPJA como um direito concreto requer a formulação e a efetivação de políticas públicas que assegurem desde o financiamento até a sistematização do trabalho pedagógico para esse tipo de oferta educativa, o que implica necessariamente também, na constituição da área como um espaço pedagógico definido, requerendo no campo dos processos formativos uniformização do processo de formação de professores para atuar na EPJA, que se encontra imerso em uma pluralidade de contextos. Para tal, a elaboração de uma proposta de formação de professores para atuar na EPJA implica em tomar o referencial crítico da área como elemento precípuo para a constituição de um campo pedagógico próprio. É fundamental que o professor da EPJA tenha em sua formação uma compreensão clara sobre as situações de aprendizagens desenvolvidas na vida adulta, como se apropriar e selecionar tais aprendizagens, considerando esses elementos em suas práticas pedagógicas.
\end{abstract}

Palavras - chave: América Latina; Formação de professores; Políticas públicas; Práxis pedagógica.

\begin{abstract}
In this study we aim to present, through a panoramic analysis, the main trends and tensions existing in the field of teacher training for the Education of Young and Adult People (EPJA) in Latin America. The recognition of EPJA as a concrete right requires the formulation and implementation of public policies that ensure everything from financing to the systematization of pedagogical work for this type of educational offer, which necessarily implies also, in the constitution of the area as a defined pedagogical space, requiring, in the field of formative processes, standardization of the teacher training process to work at EPJA, which is immersed in a plurality of contexts. To this end, the elaboration of a proposal for the training of teachers to work at EPJA implies taking the critical reference of the area as a key element for the constitution of a specific pedagogical field. It is essential that the EPJA teacher
\end{abstract}


has in his training a clear understanding of the learning situations developed in adult life, how to appropriate and select such learning, considering these elements in his pedagogical practices.

Keywords: Latin America; Teacher training; Public policy; Pedagogical praxis.

Resumen: En este estudio pretendemos presentar, a través de un análisis panorámico, las principales tendencias y tensiones existentes en el campo de la formación de docentes para la Educación de Jóvenes y Adultos (EPJA) en América Latina. El reconocimiento de EPJA como un derecho concreto requiere la formulación e implementación de políticas públicas que aseguren todo, desde la financiación hasta la sistematización del trabajo pedagógico para este tipo de oferta educativa, lo que necesariamente implica también, en la constitución del área como un espacio pedagógico definido. , que requiere, en el campo de los procesos formativos, la estandarización del proceso de formación del profesorado para trabajar en EPJA, que está inmerso en una pluralidad de contextos. Para ello, la elaboración de una propuesta para la formación de docentes para trabajar en EPJA implica tomar el marco crítico del área como elemento clave para la constitución de un campo pedagógico específico. Es esencial que el maestro EPJA tenga en su formación una comprensión clara de las situaciones de aprendizaje desarrolladas en la vida adulta, cómo apropiarse y seleccionar dicho aprendizaje, teniendo en cuenta estos elementos en sus prácticas pedagógicas.

Palabras clave: América Latina; Formación de profesores; Políticas públicas; Praxis pedagógica.

\section{Introdução}

As discussões em torno da formação de professores vêm ocupando cada vez mais centralidade na agenda política dos governos e em seus desdobramentos no interior dos sistemas de ensino. Na América Latina, as pesquisas nesse campo tiveram maior expansão e visibilidade no contexto das reformas educacionais iniciadas nos países da região na segunda metade da década de oitenta e durante toda década de noventa, onde através de orientações de organismos internacionais como o Banco Mundial, passou-se a estabelecer uma racionalidade economicista em torno da reestruturação do trabalho docente, que consequentemente confluiu para o desenvolvimento de estudos e pesquisas voltados para a análise de processos formativos, gestão, profissão e trabalho docente, gerencialismo, avaliação, entre outros temas recorrentes à área.

O estudo conduzido pela UNESCO em 2012, Antecedentes y Criterios para la Elaboración de Políticas Docentes en América Latina y el Caribe, é um importante documento que permite situar a incidência desses temas no cenário recente sobre a profissão docente na região.

No ano de sua divulgação, a América Latina contava com um contingente de 6,4 milhões de professores atuando na educação primária e secundária, estimando para o ano de 2015 um 
aumento de 750.000 novos professores, buscando atender toda a demanda educativa da região, sobretudo no cumprimento da educação primária universal. O estudo apontou ainda que "la población docente en países de América Latina y el Caribe revela la heterogeneidad del professorado pero también capta diferencias y recurrencias en nivel regional" (VAILLANT, 2013, p. 188).

Nesse sentido, discutir a formação de professores no continente latinoamericano nos impõe alguns desafios de difícil enfrentamento. A diversidade regional que a América Latina comporta, manifestada por diferentes processos cultuais, linguísticos e políticos impede que pensemos esta realidade no singular, e impõe limites às generalizações.

No texto que segue, objetivamos apresentar através de uma análise panorâmica as principais tendências e tensões existentes no campo da formação de professores para a Educação de Pessoas Jovens e Adultas, relacionando os impactos das políticas educativas no processo de constituição da área na América Latina, refletindo também sobre a necessidade da constituição de um campo pedagógico próprio, assentado em referenciais teóricos e metodológicos que atendam às necessidades e especificidades dessa modalidade de educação.

\section{Formação de Professores para a Educação de Pessoas Jovens e Adultos na América Latina: trajetória recente}

No que diz respeito à necessidade da formação dos professores para atuar na Educação de Pessoas Jovens e Adultas, parece-nos que os países da região se aproximam de um consenso: o terreno continua sendo tão urgente quanto incerto em suas propostas e definições (UNESCO, 2000, 2003, 2009; MACHADO, 2000; MESSINA, 2002; CORVALÁN, 2008; INFANTE, 2010; CUNHA JUNIOR; SOARES, 2018) ${ }^{1}$.

Organizações internacionais voltadas para a EPJA como o Centro de Cooperación Regional para la Educación de Adultos en América Latina y el Caribe (CREFAL) e o Conselho de Educação de Adultos da América Latina (CEAAL), redes de estudos e cooperação internacional, a exemplo da RED-EPJA, universidades e sociedade civil têm manifestado reiteradamente sobre as condições que se apresenta a EPJA na região, apontado caminhos em torno da sua melhor constituição política e da necessidade de seu desenvolvimento em consonância com as atuais dinâmicas sociais. Nos debates gerados, é uma pauta perene a

\footnotetext{
${ }^{1}$ Veja também: Moura (2009), Oliveira e Dantas (2018), Faria (2009).
} 
necessidade da formação de pessoal para a área ${ }^{2}$.

Se, por um lado, a demanda por essa formação tem sido compreendida como uma estratégia importante para o melhoramento da qualidade dos sistemas educativos, por outro, continua se constituindo como um espaço permanente de redefinição, contraditório e tensionado, sendo propício tanto para a promoção de inúmeras experiências de práticas exitosas como para a reprodução de propostas pedagógicas que reafirmam esse segmento de ensino como um campo de trabalho secundário.

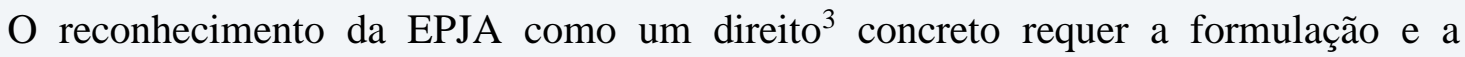
efetivação de políticas públicas que assegurem desde o financiamento até a sistematização do trabalho pedagógico para esse tipo de oferta educativa, o que implica necessariamente também, na constituição da área como um espaço pedagógico definido.

Ademais, como assinala Campero,

La formación es en elemento central para la construcción de la profesión de educador/educadora de personas jóvenes y adultas, ya que promueve en formación sólida, sistemática y específica, y contribuye en la construcción de en código ético, en la orientación del trabajo al servicio de la colectividad y el reconocimiento social del mismo. Indirectamente la formación coadyuva a la organización entre sus integrantes y al mejoramiento de sus condiciones laborales y de trabajo. Cabe señalar que la formación desempeña en papel clave en la construcción de la formación de los educadores de personas jóvenes y adultas, y es un elemento fundamental para la profesionalización del campo [...] (CAMPERO, 2015, p. 6).

A definição de um campo pedagógico próprio para a EPJA aponta, também, para a necessidade de seu fortalecimento conceitual, teórico e metodológico, garantindo que a organização do trabalho pedagógico esteja voltado especificamente para o público ao qual essa modalidade de educação atende, observando que a organização e a sistematização do conhecimento estejam alinhados na compreensão de que os demandatários por essa oferta educativa são sujeitos historicamente situados, com características heterogêneas e que carecem de condições específicas de aprendizagem.

As diversas experiências realizadas na EPJA, seja por meio da educação formal, seja no campo da educação popular, têm solicitado o perfil de um profissional de ensino, ora compreendido como educador ora como professor, que desenvolva o trabalho pedagógico primordialmente a partir de uma "base teórica sólida sobre as teorias pedagógicas" (ARROYO, 2006) que possibilite através delas uma compreensão mais ampla do processo de

2 Ver também Santos (2010).

${ }^{3}$ Ver também Rossel (2018). 
educação de adultos, de suas singularidades e particularidades.

Os estudos realizados por Messina (2002) apontam que na América Latina os professores que atuam na EPJA têm tido uma formação inicial voltada para o Ensino Fundamental e Médio, o que faz com que o campo de trabalho com adultos seja descaracterizado dos fundamentos teóricos e filosóficos que o sustentam.

O panorama atual de formação acadêmico profissional de professores para atuar na EPJA nos cursos de graduação das universidades latinoamericanas é reduzido e até mesmo escasso em alguns países, como é possível evidenciar no Chile. Do ponto de vista da formação inicial realizada por Instituições de Ensino Superior (IES) e que esteja voltada exclusivamente para a EPJA, a região conta apenas com a experiência da Universidade Pedagógica Nacional do México (UPN), que possui a carreira de licenciatura em intervenção educativa, na linha de pessoas jovens e adultas. Nas demais instituições, sejam elas públicas ou privadas, quando existentes, as disciplinas voltadas para a formação de professores para EPJA figuram como obrigatórias para o cumprimento do currículo mínimo dos cursos de pedagogia, ou de maneira optativa nas demais licenciaturas.

Em nível de extensão universitária ou pós-graduação, lato e stricto sensu, observa-se que o cenário para formação na área se alarga. Brasil, México, Colômbia, Chile e Peru (DECISIO, 2015) têm desenvolvido no âmbito das IES uma série de atividades e cursos de formação que "pueden ser útiles para reflexionar, mejorar e innovar en el diseño y puesta en práctica de propuestas formativas para educadores/educadoras de personas jóvenes y adultas" (CAMPERO, 2015, p. 8).

Embora as experiências sejam significativas e sinalize positivamente com boas perspectivas futuras, a forma com a qual a EPJA tem sido tratada no âmbito das instituições formadoras revela muito sobre a sua condição no cenário educativo. A ausência de estudos específicos voltados para a área "nem sempre alcançam uma posição de prestígio no ambiente acadêmico" (DI PIERRO, 2006, p. 288). Nesse universo, se apresentam distintas visões em torno da EPJA; particularmente na América Latina, se evidencia uma polarização em torno do seu desenvolvimento e finalidades.

Em uma leitura dos interesses conflitantes que se configuram em torno do processo de formação de professores para a EPJA na América Latina, Campero (2015) apresenta duas categorias que ilustram essa polarização: uma a que denomina instrumental, de curto alcance e caracterizada pelo atendimento imediato de objetivos, limitando a participação dos educadores ao longo do processo e outra que considera formativa, caracterizada por uma profunda 
reflexão sistemática que se configura em torno dos valores da EPJA, se apoiando no diálogo e na reflexão sobre a construção teórico-metodológica da área com vistas ao desenvolvimento de práticas que provoquem o sentido das aprendizagens.

Essa definição é análoga ao que a literatura sociológica da EPJA tem apresentado como justificativa em torno do seu processo de constituição histórica, como caracterizada por Wanderley (1985) ao apontar as correntes recuperadoras e as correntes transformadoras como pano de fundo em sua construção.

Se, por um lado, os documentos oficiais têm referenciado aos países signatários das Conferências Internacionais de Educação de Adultos (CONFINTEA) que incluam em suas pautas a diversidade na oferta e a provisão de recursos para a área, na prática, "la ausencia de políticas que articulen orgánicamente la EPJA en las redes públicas de enseñanza básica, no hay carrera específica para educadores de esta categoría educativa" (DI PIERRO; GRACIANO, 2003, p. 15), o que gera uma lacuna sobre o trabalho pedagógico com o público a qual esse tipo de ensino se destina.

Aspectos inerentes à organização do trabalho pedagógico tais como currículo, avaliação, materiais didáticos, formação de professores, entre outros têm sido concebidos na perspectiva do ensino "regular", fazendo com que as práticas dos professores sejam apenas uma transposição de uma modalidade para outra.

A esse respeito, Oliveira (1999) chama atenção para um ponto importante a ser considerado no âmbito do desenvolvimento das práticas pedagógicas destinadas ao público da EPJA, e que tem uma relação fundamental no processo de formação dos professores que irão atuar na modalidade ao afirmar que,

Currículos, programas, métodos de ensino foram originalmente concebidos para crianças e adolescentes que percorreriam o caminho da escolaridade de forma regular. Assim, a organização da escola como instituição supõe que o desconhecimento de determinados conteúdos esteja atrelado a uma determinada etapa de desenvolvimento (OLIVEIRA, 1999, p. 61)

Soares (2001) também chama atenção para essa questão quando discute a necessidade de reconhecer o perfil do aluno na EPJA para, a partir de suas realidades, fomentar "ações pedagógicas que repensem o currículo com metodologias e materiais didáticos adequados às suas necessidades e à formação de professores condizente com a especificidade da EJA" (SOARES, 2001, p. 202).

A condição de "não-criança", característica fundamental para se pensar a respeito do público da EPJA, também se torna, portanto, um elemento central para se pensar a formação do 
professor que irá atuar na área. A definição de um quadro teórico de referência, que tenha como proposta discutir e direcionar ações para um campo que carece de estudos e pesquisas mais aprofundadas, sobretudo no reconhecimento de uma demanda de educandos imersos em uma relação pedagógica em que as convergências entre cultura escolar e sistemas de aprendizagem deve fazer parte de qualquer orientação para quem irá atuar na modalidade.

Nas palavras de Oliveira (1999, p. 188):

Sem dúvida, a perspectiva assistencialista e infantilizadora da educação de jovens e adultos é um fator que prejudica a constituição do campo, limitando as condições de se ofertar aos educadores uma formação adequada, que considere as especificidades do público dessa modalidade educativa.

A perspectiva da EPJA, no âmbito da educação formal, de caráter compensatório, voltado apenas para a alfabetização de adultos, ou para escolarização daqueles que não tiveram acesso ou garantia de permanência na escola em idade considerada regular, ou ainda certificadora continua presente nas esferas formativas e apresenta relação direta com o campo da formação de professores. Com efeito, se essa é a concepção que prevalece da EPJA nos sistemas oficiais de ensino, a formação dos professores se reduz às orientações da legislação educacional, nos cursos de licenciatura e, portanto a cargo das instituições formadores (faculdades de educação, centros universitários, universidades, etc.), compreensão essa que descaracteriza e deixa de reconhecer a constituição histórica da própria modalidade, que possui raízes históricas no seio dos movimentos de educação popular e que tem uma larga trajetória formativa do educador no campo da educação não-formal.

Embora se desenvolva em caráter continuado, a formação de professores que atuam na EPJA na América Latina, na maior parte das vezes, se dá por meio de cursos oferecidos dentro dos sistemas de ensino, que possuem baixa carga horária, são pontuais e muitas vezes direcionados aos próprios programas desenvolvidos para a modalidade. São ainda verticalizados, restritos apenas à execução do trabalho voltado para o desenvolvimento de determinados projetos. Ainda pode-se dizer que são aligeirados, descontínuos e com pouco ou quase nenhum referencial que subsidie o desenvolvimento de uma prática voltada para a compreensão mais ampla da EPJA.

Un punto a destacar es que la formación es 'ofrecida' desde los propios programas, como en preparación fundamentalmente operativa u orientada hacia el 'manejo' o administración del currículo, los materiales y la evaluación; en formación instrumental y de corta duración, constituída por cursos o talleres que no están organizados en un sistema, y que prepara a los educadores más como gestores que como facilitadores (MESSINA, 2002, p. 26). 
A autora sinaliza para um ponto importante e que tem se tornado recorrente no campo da EPJA, a ausência de consistência teórica e metodológica, o que implica, de certa forma, em amadorismo, e consequentemente improviso nas práticas dos professores.

Referimo-nos ao amadorismo em questão, a ausência de conhecimentos sólidos sobre o campo de atuação e isso tem sido evidenciado à medida que a formação inicial não contempla os aspectos inerentes a modalidade. Esses aspectos, constituintes dos processos didáticos metodológicos implicam, como já mencionamos anteriormente, em não (re) conhecer além dos anseios, a maneira como se operacionaliza o ensino para aqueles que se encontram imersos no campo.

Messina (2002), ao mapear a formação inicial de professores/educadores para a EPJA na América Latina, alerta que maior parte dos países que compõe a região tem realizado essa formação em um circuito a parte da formação recebida nas universidades. Ao se referir a essa condição instalada no trato com a EPJA, afirma que:

[...] los educadores de adultos son maestros básicos o primarios o profesores de la educación media, titulados, que no cuentan con especialización en adultos y que se forman en la temática de adultos en la propia práctica. (MESSINA, 2002, p. 24).

Di Piero e Graciano (2003) em documento elaborado para o informe regional sobre a EPJA na América Latina com vistas a CONFINTEA V, também, apresentam um panorama que reafirma essa condição. As autoras advertem que:

La situación más común es que los docentes que actúan en los jóvenes y adultos son los mismos de la educación regular que intentan adaptar la metodología a este público específico o reproducen en los jóvenes y adultos la misma dinámica de enseñanza-aprendizaje que establecen en niños y adolescentes (DI PIERRO; GRACIANO, 2003, p. 75).

Existe ainda um fator importante a ser considerado no que tange à relação existente entre a formação e o trabalho com os destinatários da EPJA, e que está relacionado às condições de trabalho do professor. Em geral, a docência na modalidade se faz em virtude da complementação da carga horária dos professores que atuam no ensino diurno, com crianças e adolescentes. Esse cenário gera a "inexistencia de equipos especialmente dedicados a la EPJA impide la formación de un cuerpo técnico especializado y dificulta la organización de proyectos pedagógicos específicos para esta modalidad” (DI PIERRO; GRACIANO, 2003, p. 75).

Espinoza (2013) reafirma essa condição, apontando que, 
En cuanto a la formación docente, es en hecho que en la mayoría de los países ibero-americanos no existen ofertas amplias y diversificadas de formación docente para la EPJA. Hay acciones de formación continua, principalmente mediante las denominadas capacitaciones, que son, en gran medida, acciones remediales de la deficiente formación inicial que se brindó a los educadores de jóvenes y adultos, generalmente, en áreas de formación correspondientes a la educación de las niñas y los niños (ESPINOZA, 2013, p. 2011).

Um estudo exploratório realizado em 2007 pela Oficina Regional de Educação de Adultos para América Latina e Caribe (OREALC/UNESCO), juntamente com o CREFAL e o Instituto de Educação da UNESCO, como parte do balanço intermediário para a CONFINTEA VI, revela que os programas de formação inicial e continuada de professores para atuar na EPJA continuam ocupando um lugar marginal nas políticas de educação na América Latina.

A pesquisa mostra, ainda, que, "en la mayoría de los países, las políticas de formación de educadores de adultos no están explicitadas en los planes nacionales o programas de desarrollo social y educativo" (UNESCO, 2007, p. 48).

O relatório da pesquisa conclui que,

[...] las políticas de formación de educadores de adultos están ausentes en los programas de las universidades, donde las iniciativas que se identifican se han originado más en personas o grupos de educadores de adultos e investigadores de campo que en iniciativas institucionales. Así, en de las posibles causas del poco eco que tiene la formación inicial, y que resulta como en circulo vicioso, es que no solamente el Estado no en garantizado oportunidades de formación, sino que tampoco en garantizado oportunidades de desarrollo profesional para los que decidan formarse en el campo de la formación inicial (UNESCO, 2007, p. 11).

Por fim, a recomendação que fez o relatório foi a de que as instituições formadoras (universidades, centros universitários, faculdades de educação) e outras instituições formativas assumam a centralidade da preparação de pessoal, inicial e continuada para a área.

Concluída a CONFINTEA VI em 2009, com o balanço (CONFINTEA +6) realizado em 2016, a reivindicação dos profissionais da área por processos formativos consistentes e com um ideário pedagógico próprio permanece um dos motes para defesa de uma EPJA na América Latina que garanta aos seus destinatários os valores necessários para que assumam sua condição de participação social e cidadã. É importante salientar que esse tema continua atravessando os debates produzidos ao longo dos 60 anos de realização das CONFINTEAS.

Como pôde ser evidenciado através das discussões aqui apresentadas, os estudos realizados por diversos pesquisadores e organismos de cooperação internacional demonstram que o processo de formação de professores para atuar na EPJA está imerso em uma pluralidade de contextos. 
Questões como gestão, qualidade e eficácia da oferta educativa assumida pelos países da região, na maioria deles pelo viés das reformas educativas baseadas nas políticas neoliberais da década de 1990, fizeram com que a educação básica regular fosse priorizada frente às demais modalidades de ensino, induzindo a sociedade civil através das políticas de responsabilização para que assumisse a EPJA (a educação indígena, inclusiva, etc.) e a mantivesse ligada ao quadro das políticas sociais assistencialistas. Assim, o quadro das pesquisas que têm sido realizadas na América Latina sinaliza para que, "a pesar de los avances realizados, la EPJA sigue siendo 'el patito feo' de los sistemas nacionales de educación, de las visiones de la clase política de nuestros países" (ESPINOZA, 2013, p. 208).

A ausência de vontade política, fator que afeta diretamente a secundarização do campo, tem se colocado como um desafio para construção e efetivação de elementos pedagógicos constitutivos para a EPJA. A formação de professores está inserida nessa realidade como um desafio para superação dessa lógica e, para que essa formação efetivamente ocorra, é necessária a criação de um campo pertinente ao seu desenvolvimento, o que entendemos como conteúdos relevantes para essa formação.

\section{Conteúdos relevantes para Formação do Professor da EPJA: um campo ainda em definição}

Assentar a construção de um campo pedagógico próprio para a EPJA implica reconhecer um conjunto de elementos que justifiquem, de acordo com as características desse segmento educativo, as singularidades e particularidades que lhes são inerentes. Ou seja, que se materializam para e em seu desenvolvimento, "o que implicaria a existência de um conjunto de práticas e saberes minimamente articulados em torno de princípios, objetivos ou outros elementos comuns" (RIBEIRO, 1999, p. 185).

Tem-se atribuído com maior recorrência a essa construção a recognição de suas especificidades.

As pesquisas desenvolvidas por Soares e Soares $(2009,2011)$ a partir da análise de projetos, instituições de ensino, formação inicial e continuada de professores para a EPJA e da legislação oficial - a Constituição/1988, LDB/1996 e o Parecer CEB/2000, possibilitaram o mapeamento de uma série de expressões tais como adequado, apropriadas, características, especificidade própria, modelo pedagógico próprio, voltado para e específica, que são recorrentes e que se atribui ao campo da EPJA, sendo possível delinear a noção de 
especificidade como sendo "a convergência de aspectos que nos capacita a agir de modo próprio, produzindo algo peculiar, particular” (SOARES; SOARES, 2015, p. 4).

Nessa direção, Arroyo (2006) sustenta que o reconhecimento das especificidades implica também na formação particular do educador da EPJA e, consequentemente, em políticas direcionadas a essa formação. Portanto, o vocábulo especificidade invoca diversos elementos que podem ser considerados como conteúdos relevantes para cogitar essa formação.

Posicionamo-nos ao lado de que na formação acadêmico-profissional dos professores que atuam na EPJA, o primeiro desses elementos se refira à compreensão da EPJA como um campo político, emancipador e historicamente marcado em sua construção identitária pela forte influência dos movimentos de educação popular, onde o desenvolvimento da consciência crítica e a interpretação das realidades que geram e produzem as desigualdades fundamentam as relações sociais que reproduzem a sociedade e a própria EPJA.

Ou, como assinala Di Pierro,

A EJA deve valer-se de sua história de construção na fronteira entre os movimentos e as organizações sociais, de lado, e os sistemas educativos, de outro, inspirando-se nas experiências emancipatórias, de modo a revitalizar as estruturas e a dinâmica do espaço escolar. Esse caráter emancipador esteve presente na formação dos educadores engajados nos movimentos de educação popular desde os anos 1960, e deve ser tomado como referência, ainda que se considere que, no momento atual, nem todos os sujeitos que buscam a EJA tenham as mesmas motivações ou estejam engajados em projetos coletivos (DI PIERRO, 2006, p. 281-282).

O ideário pedagógico construído por Paulo Freire em torno da educação popular e da educação de adultos, a partir de sua pedagogia crítico-libertadora, que propõe o desenvolvimento da práxis baseada na problematização e no diálogo, constitui o pensamento educacional que melhor referência e fundamenta a dimensão política da EPJA e o seu compromisso com as características de seu público, tornando-se assim um importante elemento compositivo da formação do professor da EPJA.

A centralidade do pensamento freireano compreende uma educação não neutra, pois a mesma, quando vista sobre as dimensões da ação e da reflexão de certa existência, pressupõe a atuação do homem sobre essa realidade. O princípio da politicidade nas ideias de Freire concebe a educação como problematizadora, a qual, mediada pelo diálogo, busca a transformação através do pensamento crítico.

Para Ribeiro (1999),

Somada à consciência crítica sobre as estruturas sociais que geram a desigualdade e sobre o papel da educação na manutenção ou transformação 
dessas estruturas, a valorização do diálogo como princípio educativo, com a decorrente assimilação da noção de reciprocidade na relação professor- aluno, constitui-se pilar importante da formação do educador de jovens e adultos (RIBEIRO, 1999, p. 193).

Assimilar a natureza da EPJA como um campo que também é político, implica no reconhecimento de sua constituição histórico-sociológica, sendo fundamental que na formação do professor que irá atuar na área esteja clara essa noção. Além disso, possibilita que o professor direcione sua prática através de uma leitura e compreensão mais ampla sobre quem são os sujeitos que compõe essa modalidade, suas trajetórias socioculturais, a realidade à qual estão submetidos e os motivos que os fizeram retornar à escola.

Campero (2015) apresenta um dimensionamento sobre essa condição quando adverte que,

La EPJA es un objeto de conocimiento y de transformación. De conocimiento ya que se requiere sistematizar las prácticas y generar investigaciones para acumular saberes que permitan profundizar en él para apoyar la toma de decisiones sobre políticas, programas y acciones, además de plantear nuevas líneas de indagación. Es objeto de transformación porque no se limita sólo a los sujetos que participan y a los procesos educativos en sí, sino que su finalidad es coadyuvar al desarrollo basado en principios de respeto a la dignidad del ser humano y de justicia social, en la búsqueda de la transformación social (CAMPERO, 2015, p. 506).

A autora nos ajuda a reforçar a compreensão da EPJA como um segmento da educação onde o político e o ideológico se convergem, e que se apresenta em constante movimento, o que reafirma a necessidade de uma reflexão perene sobre sua (re) configuração, não se limitando apenas aos sujeitos participantes do processo, mas sobre as razões de suas finalidades como objeto de transformação social, gerando e legitimando politicamente sua dinâmica emancipatória (ARROYO, 2006).

Elaborar uma proposta de formação de professores para atuar na EPJA implica em tomar o referencial crítico da área como elemento precípuo para a constituição de um campo pedagógico próprio. Essa noção parece ser a base para o desenvolvimento de outros elementos como currículo, metodologias, condições de aprendizagem, materiais didáticos, formas de avaliação, temas a serem abordados entre outros aspectos, a fim de que as relações entre a formação e a prática possam produzir uma relação com o saber, o qual segundo Charlot (2005, p. 45), se materializa pela "relação com o mundo, com o outro e consigo mesmo, confrontando com a necessidade de aprender" ou, nas palavras de Campero (2008, p.16), se reconheça "el carácter social; el desarrollo de conocimientos, habilidades y actitudes; la reflexión sobre los mismos y de las experiencias 92 y, la aplicación de éstos en la práctica cotidiana”. 
Outro elemento que defendemos como pertinente e relevante na constituição do campo pedagógico para a EPJA e que consequentemente deve estar presente na formação de professores que irão atuar na área, está voltado à compreensão de como se relacionam os mecanismos psicossociais e culturais nas situações de ensino-aprendizagem na vida adulta.

Ribeiro (1999), ao denominar como "ideias-força" as condições necessárias para delinear o processo de formação de professores para atuar na EPJA, nos chama à atenção para a compreensão das necessidades de aprendizagem características da idade adulta, apresentando uma perspectiva sociológica e psicológica implicadas no processo de desenvolvimento cognitivo dessa fase da vida.

A especificidade do modo de aprender na vida adulta se processa em estruturas cognitivas anteriormente já experienciadas pelos indivíduos. Elementos como memória, percepção, atenção e juízo já são partes integrantes de uma construção fisiológica do corpo e, como reflexo, de traços psicológicos, culturais e comportamentais internalizados e assumidos ao longo de suas trajetórias.

Os conteúdos explorados nas disciplinas destinadas ao estudo da psicologia da educação, presente nos cursos de formação de professores, são na maioria das vezes voltados para o estudo das teorias do desenvolvimento e da aprendizagem de crianças e adolescentes, seja pela ausência de maiores aportes teóricos para área e que estejam destinados a compreender como aprendem os adultos, ou por outro lado, devido ao enfoque central dos cursos de pedagogia, que limita-se em estudar apenas ensinar para os estágios de vida das crianças. Assim, as práticas pedagógicas que vão sendo desenvolvidas na EPJA acabam tomando como referencial teórico-metodológico os mesmos esquemas de aprendizagem implicados em estágios de vida que não a adulta

Ribeiro aponta (1999) que:

[...] o amadurecimento de uma psicologia dos adultos, tanto no que se refere à dimensão cognitiva quanto motivacional, seria fundamental para se superar a concepção de que o desenvolvimento é algo que ocorre apenas durante o período de desenvolvimento biológico intenso (infância e adolescência), fazendo parecer irrelevantes as características específicas de outras fases da vida e os efeitos que a aprendizagem pode produzir também durante a idade adulta. (RIBEIRO, 1999, p. 194).

Também sobre essa questão, Oliveira (1999) argumenta em prol do reconhecimento de algumas condições importantes para compreender como jovens e adultos pensam e aprendem: o seu estado de não criança, o fato de terem sido excluídos da escola, e o pertencimento a determinados grupos culturais. 
Brundage e Mackeracher (1980) apud Infante (2007) defendem a existência de diversas variáveis (sociais, psicológicas, fisiológicas, etc.) presentes na vida adulta e que são determinantes para que sejam identificadas como características de seus processos de aprendizagem. Argumentam que os adultos têm numerosas experiências de vida já estruturadas que limitam novas aprendizagens, fazendo com que estes focalizem basicamente em estender os significados, valores, habilidades e estratégias adquiridas em aprendizagens anteriores. Dessa forma, assinalam para que as necessidades de aprendizagem na vida adulta estejam relacionadas às características de suas próprias vidas, de suas necessidades pessoais, de produção e de autodefinição.

Nesse mesmo sentido, Martínez (1997) apresenta uma série de conceitos advindos do campo da psicologia e da sociologia para tentar definir o que constitui a idade adulta. $\mathrm{O}$ autor advoga em seu estudo que assumir a condição adulta implica uma série de fatores que se relacionam não apenas à idade cronológica ou biológica como uma etapa da vida, mas às atividades funcionais empreendidas ao longo da vida social, de uma época, ou de uma cultura particular, estabelecendo assim uma relação idiossincrática.

Além disso, "los adultos son más proclives a expresar sus propias necesidades y a describir sus procesos de aprendizaje a través de formas verbales, lo cual les permite negociar la planificación de sus programas de aprendizaje" (INFANTE, 2007, p. 25).

Embora exista um consenso entre pesquisadores da área (RIBEIRO, 1999; OLIVEIRA, 1999; FONSECA, 2007; INFANTE, 2007) no sentido que são incipientes os estudos teóricos voltados para uma melhor compreensão sobre a psicologia da aprendizagem de adultos, está evidente também para esses autores a necessidade de compreender as particularidades da vida adulta e suas implicações nos processos de aquisição do conhecimento e do desenvolvimento das aprendizagens que devem ser consideradas importantes para orientar a formação de professores para a área.

Coadunamos com as ideias de Ribeiro (1999) quando postula que a psicologia históricocultural de Vygotsky (1996) talvez melhor se adeque para fundamentar, a priori, as propostas educativas destinadas à EPJA, uma vez que o pesquisador russo compreende o ser humano na sua dimensão onto e filogenética, com uma constituição biológica específica, mas ressignificada nas relações construídas culturalmente e socialmente. É importante salientar que a psicologia histórico-cultural não se restringe à aprendizagem escolar, mas concebe a educação como um processo amplo, presente também na mediação entre os indivíduos com a sociedade, relação essa que garante diferentes aprendizagens. 
Assim, propor estudos voltados para o modo como os sujeitos da EPJA aprendem, suas reais necessidades e expectativas em relação às finalidades da escola, requer uma visão ampliada sobre os sentidos e significados da educação na vida dessas pessoas, sobre a relevância dos conteúdos a serem aprendidos e a importância de apropriá-los ou não em face da vida que possuem.

É fundamental que o professor da EPJA tenha em sua formação uma compreensão clara sobre as situações de aprendizagens desenvolvidas na vida adulta, como se apropriar e selecionar tais aprendizagens, considerando esses elementos em suas práticas pedagógicas, dessa forma, "estariam mais aptos, assim, a fazer escolhas pedagógicas mais acertadas diante da premência que caracteriza as necessidades de aprendizagem de jovens e adultos, mediante suas condições reais de dedicação aos estudos” (RIBEIRO, 1999, p. 195).

As duas condições que apresentamos aqui, traduzidas na necessidade de compreensão política do campo e no reconhecimento das implicações presentes no desenvolvimento da relação ensino-aprendizagem característica dos adultos, em nosso entendimento, podem se constituir como um limiar para se pensar a construção de um campo pedagógico próprio, isso porque a partir desses elementos se articulam outras condições presentes na organização do trabalho pedagógico destinado a EPJA, como aponta Machado,

[...] a interdisciplinaridade, a dialogicidade, a "diversidade subjetiva" cultura -, a transformação do sujeito e suas relações sociais, a centralidade no trabalho como produção social, na escola, como objeto de análise/espaço de trabalho e efetivação do direito à educação (MACHADO, 2008, p. 162).

Alvarenga (2015), apresentando suas preocupações sobre essa questão, nos adverte que "é necessário darmos continuidade e densidade as nossas reflexões sobre o tema, uma vez que a organização verticalizada e fragmentada dos currículos dos cursos de Pedagogia e licenciaturas se confrontam com uma tradição contraria a esta organização" (ALVARENGA, 2015, p. 19).

De acordo com Soares (2007, p. 1), “a formação de um profissional voltado para as necessidades dos sujeitos jovens e adultos nos últimos anos tem se colocado como questão central nos debates sobre o tema".

Transcorrido uma década, a análise dos trabalhos contidos nos anais do V Seminário Nacional sobre Formação de Educação de Adultos, locus do fomento de discussões mais recentes sobre esse tema, realizado no Brasil em 2015, nos permite afirmar que ao tempo que se continua a reivindicar condições necessárias à formação do professor da EPJA, sinaliza para o alargamento cada vez maior da lacuna existente nos cursos de pedagogia em relação área. 
A partir da convergência de elementos políticos e pedagógicos, marcados por diversas tendências e tensões, que emergem outros fundamentos do qual o professor da EPJA precisa ter assegurado em sua formação, como a noção de que "a recuperação do direito a educação nunca vem descolada da luta pela conquista dos demais direitos” (DI PIERRO, 2006, p. 282), sendo necessária uma discussão perene sobre a história da construção dos direitos humanos, sociais e culturais, levando em consideração que na maior parte das vezes a ausência dessas garantias é o que acaba sendo o objeto central do retorno dos alunos à escola. Na tentativa de fazer com que esse objetivo se cumpra, a formação deverá fomentar o desenvolvimento de experiências que articulem os conhecimentos socialmente valorizados com aqueles que são produzidos e desenvolvidos em diversos contextos no qual os sujeitos da EPJA encontram-se inseridos.

A formação do professor da EPJA “ainda se configura particularmente pelas e nas experiências no trabalho, confrontadas com os pressupostos teóricos que possam contribuir com as demandas do cotidiano e da pratica social" (LAFFIN, 2015, p. 50) e, dessa forma, continua sendo "um campo aberto", como afirma Arroyo (2006), apresentando equidistância entre a construção de um campo específico de formação e as reais necessidades dos sujeitos que o segmento atende.

\section{Algumas considerações (in) conclusivas}

Os escritos sobre a EPJA na América Latina apresentam uma convergência uniforme em defesa da alfabetização e da escolarização das pessoas como direito humano fundamental e que possa assegurar o exercício de outros direitos.

Essa missiva atravessa os diversos documentos e instrumentos de referência produzidos ao longo dos anos desde a realização da Conferência Mundial de Educação para Todos, realizada em Jomtien, na Tailândia, em março de 1990. Dessa conferência se herdou, dentre outras perspectivas, o entendimento de que as pessoas jovens e adultas precisam estar inseridas em um projeto educativo básico que atendam suas reais necessidades de aprendizagem com vistas à efetiva participação social.

Assim, os direitos à educação e à aprendizagem para essas pessoas passaram a se constituir como um elemento fundamental para garantir o acesso à informação, à aquisição de conhecimentos e, fundamentalmente, se tornarem base para aquisição de novas habilidades para a vida.

Na América Latina, a realidade dos demandatários da EPJA não se distancia da pobreza 
na região. A superação da pobreza requer, entre outros fatores, modificações das relações sociais e estruturais advindas de um contingente de pessoas que continua à margem dos direitos básicos fundamentais. Assim, assegurar o direito educativo ao público a que se destina a EPJA também é construir aportes para superar as desigualdades que historicamente os fizeram sujeitos ${ }^{4}$.

A definição de um campo pedagógico próprio para a EPJA e a formação de professores que nele possa atuar sistematicamente são elementos imprescindíveis para o cumprimento desses objetivos.

\section{REFERÊNCIAS}

ALVARENGA, M. S. Política nacional para a formação de educadores de jovens e adultos: processo $s$ formativos na arena de disputas de sentidos. In: Anais do V Seminário Nacional Sobre Formação de Educadores de Jovens de Adultos: Formação de educadores de jovens e adultos na perspectiva da educação popular. UNICAMP/FE, 2015 CD-ROM.

ARROYO, Miguel. Formar educadoras e educadores de jovens e adultos. In: SOARES, Leôncio (org.) Formação de Educadores de Jovens e Adultos. Belo Horizonte:

Autêntica/SECAD-MEC/UNESCO, 2006.

CAMPERO, Carmem. Diseño curricular por competencias de una licenciatura para educadores de adultos. Decisio, México n. 16 p.56-61 jan/abril 2008.

CAMPERO, Carmem. La formación de los educadores y educadoras de personas jóvenes y adultas en Latinoamérica: aportes desde la investigación y la experiencia. Revista Brasileira de Estudos Pedagógicos, Brasília, v. 96, n. 244, set./dez. 2015.

CORVALÁN, Javier. Situación presente de la educación de personas jóvenes y adultas en Chile. México: CREFAL, 2008.

CUNHA JUNIOR; Adenilson Souza; SOARES, Leôncio José Gomes. Estudos comparados: notas sobre a formação de professores para a educação de pessoas jovens e adultas no estado da Bahia (Brasil) e na região de Valparaíso (Chile). Práxis Educacional, Vitória da Conquista, v.14, n. 27, jan./mar. 2018. Disponível em:

http://periodicos2.uesb.br/index.php/praxis/article/view/2927. Acesso em: 10 de maio de 2019.

DI PIERRO, Maria C. Contribuições do I Seminário Nacional de Formação de

Educadores de Jovens e Adultos. In: SOARES, Leôncio (org.) Formação de Educadores de Jovens e Adultos. Belo Horizonte: Autêntica/SECAD-MEC/UNESCO, 2006.

\footnotetext{
${ }^{4}$ Ver também Sampaio (2009).
} 
DI PIERRO, Maria C.; GRACIANO, Mariângela. A educação de jovens e adultos no Brasil. Informe apresentado à Oficina Regional da UNESCO para América Latina y Caribe. São Paulo, Brasil - Junho de 2003.

ESPINOZA, César P. Educación de adultos en América Latina y el Caribe: utopías posibles, pasiones y compromisos. México: Ed. CREFAL, 2013.

FARIA, Edite Maria da Silva de. O percurso formativo dos professores/pesquisadores da EJA na contemporaneidade. Práxis Educacional, Vitória da Conquista, v.5, n. 7, jul./dez. 2009. Disponível em: http://periodicos2.uesb.br/index.php/praxis/article/view/607. Acesso em: 12 de março de 2019.

FONSECA, Maria da Conceição F. R. Educação Matemática de Jovens e Adultos: Especificidades, desafios e contribuições. 2 ed. Belo Horizonte: Autêntica, 2007.

INFANTE, Consuelo Undurraga. ¿Como aprenden los adultos?: una mirada psicoeducativa. Universidad Católica de Chile, 2007.

INFANTE, M. I. Alfabetización de Jóvenes y Adultos en América Latina: Diagnósticos y perspectivas. In: Seminário Internacional sobre Educação e Escolarização de Jovens e Adultos. São Paulo: IBEAC, 2010.

LAFFIN, Maria Hermínia L.F. Formação inicial de educadores no campo da educação de jovens e adultos: espaço de direito e de disputas. In: Anais do v Seminário Nacional sobre Formação de Educadores de Jovens e Adultos: Formação de educadores de jovens e adultos na perspectiva da educação popular: UNICAMP/FE, 2015 CD-ROM.

MACHADO, Maria Margarida. A prática e a formação de professores na EJA: uma análise de dissertações e teses produzidas no período de 1986 a 1998. Anais da $23^{\mathrm{a}}$ Reunião Anual da Anped: Edição eletrônica. Caxambu, 2000.

MARTÍNEZ, Maria Josefa C. Didáctica y Educación de Personas Adultas. Madrid: Ediciones Aljibe, 1997.

MESSINA, Graciela. La formación de los educadores de las personas jóvenes y adultas: El camino de la reflexión desde la práctica. Santiago: Cátedra Jaime Torres Bodet, 2002.

MOURA, Tania Maria de Melo. Formação de educadores de jovens e adultos: realidade, desafios e perspectivas atuais. Práxis Educacional, Vitória da Conquista, v.5, n. 7, jul./dez. 2009. Disponível em: http://periodicos2.uesb.br/index.php/praxis/article/view/601. Acesso em: 22 de março de 2019.

OLIVEIRA, M. K. Jovens e adultos como sujeitos de conhecimento e aprendizagem. Revista Brasileira de Educação, nº. 12, Rio de Janeiro, Set/Out/Nov/Dez, 1999.

OLIVEIRA, Marta Kohl de. Vygotsky: Aprendizado e desenvolvimento: um processo Sócio- histórico. São Paulo: editora Scipione, 1995.

OLIVEIRA, Maria Olivia de Matos; DANTAS, Tania Regina. Formação docente, práxis pedagógica no contexto midiático da EJA. Práxis Educacional, Vitória da Conquista, v.14, n. 
27, jul./set. 2018. Disponível em:

http://periodicos2.uesb.br/index.php/praxis/article/view/4095. Acesso em: 07 de abril de 2019.

REVISTA DECISIO. Formación de educadores y educadoras de personas jóvenes y adultas, No. 42 Septiembre - Diciembre, 2015.

RIBEIRO, V. M. A formação de educadores e a constituição da educação de jovens e adultos como campo pedagógico. Educação e Sociedade, Campinas, ano XX, n. 68, p. 184 - 201, dez. 1999.

ROSSEL, Nélida Céspedes. Por la defensa del derecho a la educación de los jóvenes y adultos en América Latina y el Caribe. Práxis Educacional, Vitória da Conquista, v.14, n. 27, jul./set. 2018. Disponível em: http://periodicos2.uesb.br/index.php/praxis/article/view/4097. Acesso em: 11 de abril de 2019.

SAMPAIO, Marisa Narcizo. Educação de jovens e adultos: uma história de complexidade e tensões. Práxis Educacional, Vitória da Conquista, v.5, n. 7, jul./dez. 2009. Disponível em: http://periodicos2.uesb.br/index.php/praxis/article/view/600. Acesso em: 13 de março de 2019.

SANTOS, José Jackson Reis dos. Especificidades dos saberes para a docência na educação de pessoas jovens e adultas. Práxis Educacional, Vitória da Conquista, v.6, n. 8, jan./mar. 2010. Disponível em: http://periodicos2.uesb.br/index.php/praxis/article/view/623. Acesso em: 22 de março de 2019.

SOARES, Leôncio J. G.; SOARES, Rafaela C. e S. O reconhecimento das especificidades da Educação de Jovens e Adultos: constituição e organização de propostas de EJA. Arquivos Analíticos de Políticas Educativas, v.22, n.66, 2015.

SOARES, Leôncio. As Políticas de EJA e as Necessidades de Aprendizagem dos Jovens e Adultos. In: RIBEIRO, Vera M. Educação de Jovens e Adultos: novos leitores, novas leituras. Campinas: Mercado das Letras, 2001.

SOARES, Leôncio. Do direito à educação à formação do educador de jovens e adultos. In: SOARES, Leôncio.; Giovanetti, Maria A.; Gomes, Nilma L. (orgs.) Diálogos na Educação de Jovens e Adultos. 2 ed. Belo Horizonte: Autêntica, 2007.

UNESCO. Antecedentes y Criterios para la Elaboración de Políticas Docentes en América Latina y el Caribe. Santiago: UNESCO, 2012.

UNESCO. La Educación de Jóvenes y Adultos en América Latina y el Caribe. Hacia un Estado del Arte. Informe Regional de América Latina y el Caribe para la Conferencia de Seguimiento a CONFINTEA V, Bangkok, septiembre de 2003. Santiago. Chile, 2007.

UNESCO; CEAAL; CREFAL; INEA. La educación de personas jóvenes y adultas en America latina y el Caribe. Prioridades de acción en el siglo XXI. Santiago do Chile, mayo. 2000. 
UNESCO-OREALC. La Educacion como un Bien Público y Estratégico. Encuentro Regional UNESCO - UNICEF. Cartagena, Del 31 de agosto al 21 de septiembre de 2003. Mimeo.

VAILLANT, Denise. Formación Inicial del professorado em América Latina: dilemas centrales y perspectivas. Revista Española de Educación Comparada, n. 22, p. 185-206, 2013.

WANDERLEY, Luiz Eduardo W. Apontamentos sobre educação popular. In: VALLE, Edênio (org). A Cultura do Povo. 3 ed São Paulo: Cortez, 1985.

\section{SOBRE OS AUTORES:}

\section{Adenilson Souza Cunha Júnior}

Doutor em Educação. Docente do Programa de Pós-Graduação em Educação da Universidade Estadual do Sudoeste da Bahia (UESB) - Brasil

E-mail: adenenilsoncunha@uesb.edu.br

(iD http://orcid.org/0000-0003-3622-1799

\section{Leôncio José Gomes Soares}

Doutor em Educação. Docente do Programa de Pós-Graduação em Educação da Universidade Federal de Minas Gerais (UFMG) - Brasil

E-mail: leonciogsoares@gmail.com

iD http://orcid.org/0000-0003-4750-2529 